\title{
MERLEAU-PONTY Y EL SENTIDO DE LO POLÍTICO
}

\section{Leonardo Eiff *}

Resumen: El trabajo se interroga por el sentido de lo político en el pensamiento de Merleau-Ponty. Con este objetivo, toma tres escritos señeros que permiten comprender dicha interrogación. El análisis de tales escritos (Lectura de Montaigne, Nota sobre Maquiavelo y el prólogo a Humanismo y terror) da cuenta del núcleo de la filosofía política merleau-pontyana más allá de las habituales periodizaciones a la que es sometida el conjunto de su obra. Ese núcleo condensa una noción de lo político como contingencia y conflicto de raíz maquiaveliana que dialoga críticamente con la tradición marxista. Por otra parte, el trabajo concluye con la hipótesis acerca de que las reflexiones merleau-pontyanas sobre lo politico se nutren de un concepto de humanismo que se sustrae a la visión heideggeriana del mismo para enmarcarse en la saga republicana del humanismo político.

Palabras clave: político, conflicto, sentido, contingencia, historia

Abstract: This paper analyzes the sense of political in the thought of Merleau-Ponty. Three very known writings (Lecture de Montaigne, Note sur Machiavel and the prologue to Humanisme et terreur) are chosen to caracterize that point beyond the customary periodizations of his work. That nucleus condenses a notion of political as contingency and conflict where the Machiavelian root enters in a critical dialogue with the Marxist tradition. On the other hand, our conclusion explores the hypothesis that Merleau Ponty's reflections about the concept of political are nourished by a notion of humanism that evades Heidegger's interpretation and it is connected with the republican saga of political humanism.

Key words: political, conflict, sense, contingency, history

\section{I}

Maurice Merleau-Ponty despliega su indagación acerca de la singularidad de lo político a través de un cierto rodeo filosófico. Es decir, no

* Licenciado en Ciencias Políticas por la Universidad de Buenos Aires (2005). Actualmente cursa el Doctorado en Ciencias Sociales (UBA) y es becario del CONICET. Dirección electrónica: leoeiff@yahoo.com.ar 
va a su objeto sino a partir de una interrogación filosófica alrededor del êtreau-monde. Pero en los tres textos que vamos a trabajar en esta oportunidad el señalado rodeo está reducido a su mínima expresión (con la relatividad excepcionalidad que puede desprenderse del texto sobre Montaigne): en ellos lo político ocupa el primer plano de la interrogación. De allí que consideremos que tales ensayos reúnen el "núcleo duro" del pensamiento político merleau-pontyano, expresando la persistencia de un estilo de compresión que atraviesa las divergencias que presentan las obras políticas mayores de nuestro autor (Humanismo y terror y Las aventuras de la dialéctica) y los contrastes -hasta el supuesto corte- entre sus dos periodos filosóficos. En suma, tenemos ante nosotros los resortes nodales de la reflexión política de Merleau-Ponty.

\section{II}

En la Fenomenología de la percepción Merleau-Ponty desarrolla una serie de reflexiones fenomenológicas acerca de lo social no sólo para desembarazarse de la perspectiva de la conciencia, sino también para acceder al terreno propio de la política. ${ }^{1}$ En el ensayo que le dedica nuestro autor a Michel de Montaigne es posible observar de manera condensada esta temática, en principio contradictoria: la perspectiva de la conciencia y el mundo de los otros; o, en otras palabras, la política y la soledad. Pues bien, detengámonos en el texto. ${ }^{2}$

Merleau-Ponty va a concentrarse exclusivamente en el libro tercero de los Ensayos de Montaigne, donde se expone con todo rigor la tensión entre la apuesta por un yo retirado del mundo y la exigencia de una vida con -y a partir de- los otros. ${ }^{3}$ Es interesante sugerir que, aunque Merleau-Ponty no lo destaque, se roza en este trabajo la tradicional contraposición entre la vita contemplativa y la vita activa. Montaigne hereda esta discusión a través de

${ }^{1}$ Ver los capítulos sobre "El otro y el mundo humano" y "La libertad", en MerleauPonty, Maurice, Fenomenologia de la percepción, México, FCE, 1957.

$2 \mathrm{El}$ texto fue publicado originariamente en Les temps modernes, $\mathrm{N}^{\circ} 27$, diciembre 1947, y recopilado en Signes, París, Gallimard, 1960 (traducción castellana: Signos, Barcelona, Seix Barral, 1964). Nosotros tomamos el texto de la versión castellana.

${ }^{3}$ Los epígrafes extraídos de los Essais son elocuentes respecto a la problemática planteada: "Je m'engage difficilment", "Il faut vivre entre les vivants". 
su frecuentación de los clásicos antiguos y parece optar por la vita contemplativa, ${ }^{4}$ a partir de su declarado escepticismo, arrojando al mundo de la acción al sitio de la inmoralidad, de la sinrazón; en suma, propone la superioridad de la instancia contemplativa -la búsqueda de la verdad vía la indagación de sí mismo- frente a la corrupción del alma a la que están condenados los practicantes de la política. Ahora bien: la problematización de esta interpretación de Montaigne es el punto neurálgico del ensayo merleau-pontyano. Se trata de despuntar el modo -a veces implícito- por el cual, en el mismo Montaigne, el pensamiento no se opone a la acción con los otros, esto es, que es posible -o mejor: indubitable- la coexistencia del pensamiento -la reflexión sobre sí- y la acción en el mundo. En suma, Merleau-Ponty va a intentar releer a Montaigne con el foco en la política, en el vivire civile del autor de los Ensayos 5 .

${ }^{4}$ Optar es una manera de decir, ya que el peso del bios filosófico en la tradición de la filosofía occidental hacía prácticamente inviable cualquier otra elección: "Con la desaparición de la antigua ciudad-estado - parece que san Agustín fue el último en conocer al menos lo que significó en otro tiempo ser ciudadano-, la expresión vita activa perdió su específico significado político y denotó toda clase de activo compromiso con las cosas de este mundo. $\mathrm{Ni}$ que decir tiene que de esto no se sigue que labor o trabajo se elevaran en la jerarquía de las actividades humanas y alcanzaran la misma dignidad que una vida dedicada a la política. Fue, más bien, lo contrario: a la acción se la consideró también entre las necesidades de la vida terrena, la contemplación (el bios theoretikos traducido por vita contemplativa) se dejó como el único modo de vida verdaderamente libre" (Arendt, Hannah, La condición bumana, Barcelona, Paidós, 2003, p. 27). Evitando implicarnos completamente en las exigentes distinciones teóricas propuesta por Arendt, nos inspiramos en sus trabajos en lo que hace a las definiciones de vita activa y vita contemplativa.

${ }^{5} \mathrm{Si}$ se nos permite el atrevimiento, ocurriría algo similar con Cicerón, quien durante toda la Edad Media fue considerado uno de los grandes exponente de la vita contemplativa, pero que, a partir de la empresa colectiva desplegada por el humanismo florentino durante el Quattrocento, y más allá, se transformó en el símbolo del espíritu cívico, enseñándoles a los hombres del Renacimiento italiano "que la obligación principal de un ciudadano es servir a su comunidad; y que la participación activa en los asuntos del Estado no debe necesariamente disminuir sus capacidades intelectuales; en realidad, debe estimularlas" (Baron, Hans, "La remembranza del espíritu cívico romano de Cicerón a lo largo de los siglos medievales y en el renacimiento florentino", En busca del bumanismo civico florentino, México, FCE, 1993, pp. 109-110). No sugiero que Merleau quiera transformar a Montaigne en el 
El ensayo comienza discutiendo la pretendida adscripción de Montaigne a la corriente filosófica del escepticismo. Decir que fue un escéptico no significa demasiado, ya que su pensamiento desborda en todo momento las fronteras de esa tradición filosófica. La meditación extrema sobre las paradojas de la conciencia de sí, del ser-conciente, fue la marca distintiva de la obra de Montaigne. El escepticismo de Montaigne es para Merleau-Ponty una filosofía de la ambigüedad. El acto de la conciencia supone una inerradicable ambigüedad entre la libertad de la conciencia y su anudamiento al mundo. En suma: soy libre pero no soy dueño del mundo. ${ }^{6}$ Hay una opacidad constitutiva de la conciencia que no puede develarse por ninguna cogitación. No hay un punto cero de la conciencia que ilumine la relación del sujeto con el mundo. El dialogo crítico consigo mismo que propone Montaigne no tiene "solución" a la vista, se realiza en un perpetuo ensayo anclado no en el entendimiento, sino en la experiencia ambigua de nosotros mismos. Como se observa, Merleau-Ponty trata de ver en las reflexiones de Montaigne una alternativa filosófica al pensamiento cartesiano. Unas páginas más adelante el antagonismo se hace explícito, y en ese "cuerpo a cuerpo" que propone nuestro autor podemos entrever a Montaigne como un fenomenólogo avant la lettre. Pero también puede leerse entrelíneas una trasfiguración del debate entre Sartre y Merleau-Ponty en las figuras de Descartes y Montaigne: la conciencia soberana y la conciencia perceptiva.

Así, mientras Descartes elige bifurcar al alma y al cuerpo para que puedan ser aprehendidos por el entendimiento en su distintiva singularidad, Montaigne se sostiene en la intemperie paradójica del alma y el cuerpo, experimentando la mélange de las "substancias", l'empiétement de una en la otra; en fin, Montaigne -a diferencia de Descartes- reflexiona sobre el sujeto encarnado, sobre la carne del mundo. De esta manera, sospecha de la claridad de la metafísica, de las recetas filosóficas que auguran una resolución para el drama humano y se inclina por la descripción de la problemática humana, por una "investigación sin descubrimiento", por el

epítome de la vida cívica, pero sí que pretende arrancarlo de las "evidencias" del escepticismo anti-político para poder pensarlo también como un hombre público. 6 "Para él, nosotros estamos interesados en un mundo del que no tenemos la llave, incapaces de permanecer en nosotros mismos y en las cosas, remitidos de nosotros a ellas y de ellas a nosotros" (Merleau-Ponty, Maurice, Lectura de Montaigne, p. 248). 
develamiento de lo inacabado en el hombre. ${ }^{7}$ Estos párrafos sobre Montaigne recuerdan el final del prólogo a la Fenomenología de la percepción cuando el filosofo francés sugiere que los grandes dilemas de la tradición filosófica son misterios y no problemas, es decir, suponen interrogaciones sin respuestas; y en consecuencia, la tarea de la filosofía es la de renovar la interrogación, ahondar en el misterio: la filosofía enseña a ver el mundo en el asombro y no en la certeza dogmática.

Ahora bien, esta interrogación sin fin a partir de sí mismo parece colocarse en las antípodas de la vida pública. Merleau sintetiza dicho antagonismo en una frase de Montaigne: "Hay que prestarse a los demás y no entregarse más que a sí mismo"». La vida pública me esclaviza al otro, la verdad es desplazada y ya no es posible vivir de acuerdo consigo mismo. Hay una locura de la política y un maleficio en lo social que hacen que sea necesario mentir, traicionar, asesinar. Montaigne reconoce esta "necesidad" pero quiere mantenerla a distancia, cavar un pozo entre ese mundo cruel que debe necesariamente organizar la vida en común y la existencia libre, porque el Estado y las leyes son imprescindibles pero al mismo tiempo son la negación de la libertad. Rechaza así el sueño platónico de reconciliar la vida pública con la razón filosófica, y, en consecuencia, Merleau-Ponty nos da una primera conclusión desalentadora de su lectura política: "Vivir en los asuntos públicos es vivir a la manera de otro. Montaigne se inclina evidentemente a vivir a su manera...".?

Pero inmediatamente siembra la duda acerca de que ésta haya sido la última palabra del autor de los Ensayos y propone un revés de la trama. Luego de caminar hacia nosotros mismos derribando dogmas y esquivando a la opinión va a producirse una vuelta al mundo. Es decir, lejos de significar la búsqueda asombrosa de sí mismo el fin de la política, dicha indagación va a

${ }^{7}$ La preocupación de Montaigne por lo inacabado, por el no-ser del hombre lo lleva a desplegar una serie de reflexiones sobre la muerte como reverso complementario de nuestro ser en el mundo. Por otra parte, considera Merleau-Ponty que este estilo de reflexión filosófica lo aleja a Montaigne de la religión como sistema estable de creencia. La única pasión religiosa que considera válida es la del misterio, porque ella se confunde con nuestra locura. Cfr. Ibid., pp. 250-253.

8 Ibid., p. 253.
${ }^{9}$ Ibid., p. 255. 
abrir el horizonte de lo público de una manera singular. ${ }^{10} \mathrm{El}$ propósito de restaurar la primacía de la experiencia de la percepción de cara a las "certidumbres" de la metafísica se completa con una revalorización del mundo de la doxa, terreno de la política, frente a la supuesta supremacía de la filosofía. Su vida concreta se nutrió de los otros, vivió -como todos- bajo la mirada de los demás. Tuvo la pasión de la amistad y no rechazó comprometerse en política. Su amistad con La Boétie le descubrió la centralidad de los otros, como estamos infestados por ellos, usurpados, arrancados de nuestro apacible ser. Los escritos de Montaigne nacieron de esa amistad, que fue el santo y seña de su reflexión intelectual. Los Ensayos se escriben a partir de la amistad y no de una celosa, huraña, soledad escéptica que rehúsa el mundo según los otros. Su compromiso con lo público se realizó bajo la premisa de que estamos condenados a vivir entre los vivos y es en este lugar donde tenemos algo que hacer. No fue un hombre de partido dice Merleau. No tenía el temperamento. Pero intentó hacer convivir el gusto por la libertad con la acción en el mundo ligada a la opinión de los otros. Convivencia ambigua, frecuentemente amarga, pero imprescindible si llevamos hasta el final la sentencia de Montaigne: il faut viure entre les vivants.

En resumen: según Merleau, para Montaigne el bien público no coincide con la razón moral. El ensayista reconoce y rechaza subjetivamente al mismo tiempo este hecho. Pero esta no coincidencia no despoja a la política de toda moral, dirá Merleau-Ponty ya maquiavelianamente, más bien vuelve evidente la necesidad de elucidar la moral propia de lo público. Dicha moral debe comenzar por reconocer la contingencia y la primacía del otro. En otras palabras, aceptar que no hay un orden arquitectónico preestablecido que dé cobijo a las acciones políticas; que, por el contrario, ellas erigen su sentido a partir de una práctica siempre acechada por la fortuna, en la oscuridad de lo histórico. Y también asumir que los asuntos públicos se enarbolan a partir del otro, esto es, que las acciones políticas son llevadas adelante por actores, juzgados por los resultados objetivos de sus acciones. Vivir en los asuntos públicos es vivir de acuerdo a un rol, a la

10 Desde ya que esta vuelta al mundo incluye una reflexión fenomenológica sobre la percepción -el sujeto encarnado- que excede el interés por los asuntos públicos, pero ya señalamos que para nosotros el punto de mayor significación se encuentra en los gestos políticos del autor y su intérprete. 
manera de otro. En lo politico prima la opinión. Merleau-Ponty descubre en Montaigne estas intuiciones acerca de lo social y lo político. Se trata, podemos sugerir, de un Montaigne lector de Maquiavelo.

Pues bien, con Maquiavelo ingresamos en el medio propio de la politica. ${ }^{11}$ En el pensador florentino se encuentra una concepción de lo politico como relación entre los hombres. Y esa vinculación se define por su dimensión conflictiva. La centralidad del conflicto torna inasible el pensamiento de Maquiavelo. Por eso, nuestro autor comienza preguntándose: ¿cómo podemos comprenderle? Maquiavelo descoloca, está siempre en otro lugar. El abismo al que nos arroja se debe a la compleja articulación que anida en su discurso alrededor del poder y la libertad. Maquiavelo busca la libertad sin dejar de reflexionar sobre el poder. Así, habla de la opresión, de la astucia, del engaño, pero en todo momento tiene in mente la posible coincidencia entre los dos polos que dan sentido a lo político.

Merleau-Ponty encuentra en Maquiavelo -adelantándose en dos décadas a Lefort- la institución política de lo social, o, en otros términos, la singularidad política del conflicto inter-humano. Citando al mismo Maquiavelo dirá que el pasaje de los animales a los hombres es el pasaje del combate con la fuerza al combate con las leyes: "Los hombres viven en el horizonte del Estado y de la Ley".12 El vivir humano se define por el combate entre -dicho en lenguaje filosófico- un yo y otro, lo mismo ocurre con el vivire político en las figuras del Príncipe y sus súbditos. Pero este conflicto constitutivo no se da entre dos mónadas, sino entre sujetos entrelazados. El conflicto supone la comunión. Con la lógica propia de la política no sucede nada distinto, el poder del Príncipe que aparece desgajado de los súbditos - como el yo que se enfrenta al otro-, no tiene otro origen que el que surge de la trama societal. Tal es el descubrimiento de Maquiavelo: el Poder no posee un fundamente trascendente, está amarrado al drama de la lucha social. Por eso, el dominio del Príncipe es siempre inestable, corroído en todo momento por las volteretas de la Fortuna. La

${ }^{11}$ Merleau-Ponty, Maurice, "Nota sobre Maquiavelo" en Signos, p. 268. Este ensayo surge de una comunicación titulada "Maquiavelismo y humanismo", leída en el Congreso Unanesimo e scienza política, Roma-Florencia, septiembre 1949.

12 Ibid., p. 266. 
aparente crueldad del secretario florentino no emerge de otro lugar que no sea de esta certeza acerca de la realidad del Poder.

En la Fenomenología de la percepción se describe el nacimiento de la vida común a través de una indagación sobre el cuerpo y el lenguaje, y no hay duda de que estas descripciones contienen una importancia política decisiva ${ }^{13}$. Ahora bien, con el "momento maquiaveliano" de nuestro autor vemos cómo se ilumina lo político en cuanto tal. El autor de El príncipe no describe meramente el funcionamiento de la técnica del poder, sino el nacimiento de una vida común, nacimiento que para ser propicio -es decir, republicano popular- deber sortear las mistificacione y mirar de frente el conflicto.

Merleau-Ponty inclina sus reflexiones hacia el problema del poder, más que a la institución de una vida política libre en la tradición republicana; de allí que la mayoría de las citas sean de El principe. Sin embargo, y es en algún sentido sorprendente, las cuatro apelaciones a los Discorsi se realizan a través de citas indirectas tomadas del Maquiavelo de Renaudet ${ }^{14}$. Nuestro autor parece adscribir a la idea de una bifurcación en el pensamiento maquiaveliano, entre un lado principesco y otro republicano, cuando observa que "Maquiavelo no dice nada más sobre las relaciones entre el poder y el pueblo en El príncipe. Pero sabemos que es republicano en los Discursos sobre Tito Livio". ${ }^{15}$ Luego de marcar esta diferencia, señala sin embargo que el punto de posible unión es la noción de virtud como medio de vivir con los otros. Un momento antes había sostenido que la única apelación maquiaveliana a las relaciones entre Príncipe y pueblo era la famosa frase del capítulo IX acerca de los dos humores del pueblo que no quiere ser oprimido, y finalmente que el Príncipe sustentará mejor su poder con el apoyo del pueblo antes que con el apoyo de los Grandes. MerleauPonty tiene muy claro que la noción de virtud se ancla en la tradición antigua

${ }^{13}$ Ver: Peillon, Vincent, La tradition de l'esprit. Itinéraire de Maurice Merleau-Ponty, Paris, Grasset, 1994.

14 Augustin Renaudet publicó en 1942 un amplio estudio sobre Maquiavelo que tuvo un fuerte impacto en el ambiente intelectual francés. Es citado por Althusser y trabajado por Lefort dentro de la parte dedicada a las "interpretaciones ejemplares". En el momento de la conferencia de Merleau-Ponty (1949) era el más destacado dentro de los estudios franceses sobre Maquiavelo, de allí las constantes referencias. ${ }^{15}$ Merleau-Ponty, "Nota sobre Maquiavelo", p. 268. 
del vivire civile. No indaga en la revolución maquiaveliana respecto a las antiguas concepciones de la virtud, pero sí tiene presente la novedad del enfoque ${ }^{16}$. También deja pasar la radicalidad del concepto de nodominación, del pueblo que no quiere ser oprimido, que todo el republicanismo del siglo XX trabaja en profundidad. A pesar de ello, podemos sospechar que Merleau-Ponty sabe que en las ideas de virtud y pueblo yace el núcleo de la ruptura maquiaveliana.

Como dijimos, nuestro autor se preocupa en primer término por hallar el medio propio de la política: "Maquiavelo no pide que se gobierne con los vicios, la mentira, el terror, la astucia, trata de definir una virtud política"17. Esta virtud política es la virtù-se sabe: el conjunto de cualidades que hacen conservar a un Príncipe y/o a un pueblo su estado-, y también una moral pública, un humanismo político. De esta manera, Merleau-Ponty -como bien nos apunta Rinesi ${ }^{18}$ - logra destrabar (décadas antes de las lecturas republicanas de los años 70) el doble corsé que oprimía las lecturas sobre el florentino: una, de tradición jesuítica, hacía de los escritos de Maquiavelo un conjunto de reglas inmorales que apuntaba a la destrucción de toda ética comunitaria; la otra, típicamente moderna, decimonónica, hacía de Maquiavelo el símbolo originario de la separación entre política y moral. Pues bien, Merleau-Ponty juega a dos bandas y rompe filas con esta doble tradición de oposición simétrica. Veamos cómo.

Lo fundamental en Maquiavelo es el descubrimiento de que la política transcurre y se define en la vida concreta de los pueblos y no en el cielo abstracto de las buenas intenciones. Pero este descubrimiento fue posible porque Maquiavelo desterró la ontología clásica del buen orden, estable y armónico. Lo concreto en política es la opinión y la contingencia. El conflicto, el antagonismo y la lucha están en el origen de lo social, porque la contingencia es el índice de la vida común. El conflicto emerge también de la singular interacción entre los hombres: la opinión y la apariencia. La radicalidad maquiaveliana, sostiene Merleau-Ponty, deviene de autonomizar el reino de la apariencia y transformarla en la verdad de la política.

16 Ver Skinner, Quentin, Maquiavelo, Madrid, Alianza 1981, pp. 44-55.

${ }_{17}^{17}$ Merleau-Ponty, "Nota sobre Maquiavelo", p. 272.

18 Rinesi, Eduardo, Politica y tragedia, Buenos Aires, Colihue, 2003, pp. 40-43. 
El ejemplo princeps seleccionado es el pasaje de César Borgia que tenía fama de cruel, pero debido a su crueldad contenida puso en orden a la Romagna. Así, lo que parecía una conducta inmoral -la crueldad- se transformó en una suma bondad porque tuvo como resultado el orden público y la paz social. $\mathrm{Y}$ esto es así porque los actos políticos transcurren no en un orden dado sino en una situación siempre cambiante, en un determinado estado de la opinión. Por eso, la mera bondad puede ser destructiva y la crueldad beneficiosa para la vida en común. En este punto, Merleau-Ponty realiza una analogía entre la apariencia política y la percepción fenomenológica, ambas dóxicas y ambas desestructurantes del logos entendido como armonía, como lo uno frente a lo múltiple. Aquí es al revés. La contingencia supone la multiplicidad de las producciones sociales, multiplicidad encontrada, en conflicto. Tal el drama de la política: dar sentido a un mundo en pugna. Hablamos de drama, pero sería mejor hablar de tragedia: "Los actos del poder, reflejados crean una apariencia que es el lugar propio y en suma la verdad de la acción histórica. El poder lleva a su alrededor un halo, y su desgracia -como la del pueblo que tampoco se conoce-, es la de no ver la imagen de sí mismo que ofrece a los demás. Es pues una condición fundamental de la política desarrollarse en las apariencias". ${ }^{19}$ No hay entonces una verdad política por fuera del reino de las apariencias: somos como nos ven. Y lo importante es conocer cómo nos ven, porque no podemos vernos sino es a través de la mirada de los otros. Merleau-Ponty enumera entonces los consejos maquiavelianos acerca de cómo el Príncipe debe mostrar su poder. Porque ese mismo poder no está fundado más que en una apariencia, sujeta a cambios: la opinión popular. $Y$ la opinión, que no puede ver más que los resultados -los concretos reflejos de la apariencia-, juzgará de acuerdo con ellos.

Maquiavelo, dice nuestro autor, nos da esta sabiduría que supera el principismo político -el moralismo kantiano-y nos abre paso, no hacia una cruda política inmoral, sino hacia una moral concreta, pública, que sabe de los vértigos de la vida colectiva pero aun así apuesta por la virtud de los hombres.

Hay para Merleau-Ponty, entonces, una segunda paradoja en el seno del pensamiento maquiaveliano. La primera, recordemos, surgía de la

${ }^{19}$ Merleau-Ponty, “Nota sobre Maquiavelo”, pp. 270-271. 
distancia entre los propósitos y los resultados de una acción que no necesariamente guardan un correlato. La segunda, nace de la descripción de una práctica política maniatada en un mundo contingente y aparente y al mismo tiempo la visión de la acción humana como libertad: "Lo que hace que no comprendamos a Maquiavelo, es que une el sentimiento más agudo de la contingencia o de lo irracional en el mundo con el gusto de la conciencia o de la libertad en el hombre". ${ }^{20}$ ¿Cómo puede convivir ese azar, esa fortuna que como un río inunda todo, con la libertad de los hombres para instituir lo común? Pues bien, es que la fortuna no juega más que en los puntos ciegos de la virtud, es la forma que toma nuestro desconocimiento de los hombres, de los tiempos. La fortuna no es una Diosa exterior, anida en el reverso de nuestra virtud. Así, la única manera de conjurarla es develar los principios mismos de la institución de lo social. Los que no comprenden a Maquiavelo son los que creen que puede haber una razón de espaldas a la sin-razón, un orden sin la contaminación de lo contingente, en suma, una moral sin política -o una política sin moral-, un sujeto sin mundo.

Merleau-Ponty entonces les "devolverá la pelota", como dice Rinesi, a los moralistas y a los que ven en lo político maquiaveliano una mera técnica de ejercicio del poder. Maquiavelo también con sus consejos principescos despunta una moral, o un verdadero humanismo, en tanto iluminó el sitio auténtico de la práctica política, donde coincide con la virtud pública: en la relación entre los hombres. El secretario florentino es un humanista radical, porque le quitó toda ancla trascendente al ser humano -al poder políticoarrojándolo a la intemperie de la contingencia y el conflicto, dejándolo sólo con su humana virtud.

Es el carácter inmanente del mundo político maquiaveliano lo que vuelve insoportable su asunción por los políticos liberales, dirá MerleauPonty. Si preguntamos ¿quién sostiene los principios enunciados?, ¿cómo van a ejecutarse?, ¿con qué hombres y prácticas?, el cielo abstracto de las declamaciones se obscurece. Merleau-Ponty cita un ejemplo: el problema de la esclavitud durante la revolución francesa. Los principios y valores de la Declaración Universal de los Derechos del Hombre se toparon con los beneficios económicos que traía la esclavitud para la sociedad francesa y con la guerra de esta última con Inglaterra. Sólo el combate de los esclavos

${ }^{20}$ Ibid., p. 272. 
haitianos puso entonces en apuros la contradicción entre unos valores y una práctica. El mismo Napoleón mandó una flota para restablecer la esclavitud en nombre de la Revolución y Toussaint-Louverture fue acusado de agente del extranjero ${ }^{21}$. Es que el drama de la política no nace de una lucha entre valores nominales contrapuestos, sino en el combate por el sentido divergente de unos valores que todos comparten. Maquiavelo vio esto; Merleau-Ponty, su fino lector, también.

Para terminar, nuestro autor erige una saga que va de Maquiavelo a Marx y de éste a la revolución bolchevique, con el foco puesto en los problemas de un humanismo real. En las dos últimas páginas del ensayo vemos condensados los dilemas políticos del fenomenólogo francés, que oscilaba entre la confianza en las potencialidades emancipatorias del marxismo y la reserva respecto a lo que acontecía en la Rusia soviética. Consideramos que Maquiavelo pone una cuña en esta situación dilemática.

Merleau-Ponty comienza por los límites del humanismo político maquiaveliano, que se contentó con buscar un poder que no sea injusto sin definirlo acabadamente; quizás, sostiene nuestro autor, por la convicción acerca de la inmutabilidad de los tiempos y de los hombres. En este punto, Merleau-Ponty empobrece su lectura de Maquiavelo para realizar más rápidamente el pasaje a Marx. Así, el filósofo alemán habría retomado el humanismo real maquiaveliano, historizándolo y poniendo en el lugar del poder a los sin poder, en el lugar del Príncipe al proletariado. La apuesta marxiana del reconocimiento del hombre por el hombre a través de la revolución proletaria supone una profundización virtuosa respecto de los audaces consejos maquiavelianos. El legado de Marx -y Maquiavelo- es recogido por los hombres políticos del Octubre ruso que tienen la tarea de crear en la práctica nuevas formas políticas. Pero ocurre, dice MerleauPonty, que luego de los acontecimientos de Cronstadt "el poder revolucionario perdió contacto con una fracción del proletariado, y, para

${ }^{21}$ Merleau-Ponty se apoyó en el conocido libro de C. L. R. James Los jacobinos negros que narra los acontecimientos de la Revolución haitiana. El libro fue comentado en Les temps modernes con polémica incluida: "Les jacobins noires" en Parcours 19351951, París, Verdier, 1997, pp. 125-133. Respecto de las relaciones entre la revolución francesa y la revolución haitiana, véase Grüner, Eduardo, La oscuridad y las luces. Capitalismo, cultura, revolución, Buenos Aires, Edhasa, 2010. 
ocultar el conflicto, empezó a mentir"22. El poder político de los bolcheviques se vuelve un poder similar al que creía combatir inspirándose en Marx, y como toda política al margen del pueblo ocultó el conflicto constitutivo y lo transformó en espionaje, conspiración, y a los proletarios en lucha en meros agentes de la reacción. Estos hechos parecen entonces darle la razón a Maquiavelo que no creía posible la liquidación de todo poder separado de lo social. La reabsorción marxiana de la política en lo social a través de la revolución de los sin-poder se demuestra falsa en la Rusia de Lenin; y Merleau-Ponty, para no terminar de cortar amarras con la promesa marxista, apela a la incertidumbre respecto de si el fracaso se debió a una inocencia letal de la teoría o a las condiciones contingentes de la Revolución rusa. Como sea, endereza de vuelta el timón: ahora (1949) cuando Cronstadt se ha vuelto sistema, y la élite stalinista construye el "socialismo" sin contacto alguno con el proletariado parece indispensable volver a Maquiavelo. En suma, en estas dos breves páginas nuestro autor va de Maquiavelo a Marx, y, luego de ver al marxismo en acción, de Marx a Maquiavelo, para concluir que el pensador florentino ha diseñado algunas de las coordenadas de todo humanismo serio, contribuyendo a la claridad política $y$, sobre todo, que esas coordenadas no han sido superadas por Marx.

Es alta la tentación de darle a este pasaje de manos una interpretación lefortiana y sostener que el camino de Maquiavelo a Marx se ancla en la ilusión de una superación del conflicto -de la política- a través de la creencia metafísica en la reconciliación y el reconocimiento del hombre por el hombre, y, por el contrario, la vuelta de Marx a Maquiavelo va de suyo con el descubrimiento de la insuperabilidad del conflicto y del carácter inevitablemente tensionado del vínculo entre el poder político y lo social. Merleau-Ponty entonces se movería entre la ilusión marxista y la cruda veracidad maquiaveliana. Pero ¿es posible afirmar sin más la inocencia marxista de nuestro autor? Porque quizás Merleau-Ponty sea demasiado conciente de las flaquezas políticas del marxismo, y es por ello que va y viene respecto a Maquiavelo, buscando maquiavelizar a Marx. En este sentido, podemos recurrir a otro texto en donde se ve este intento -con las oscilaciones del caso-, junto a otra muestra de lo que Merleau-Ponty entiende por humanismo real, nosotros diríamos político.

22 Merleau-Ponty, "Nota sobre Maquiavelo”, p. 278. 
El texto es el prólogo a Humanismo y terror, ${ }^{23}$ que oficia también de respuesta a las diatribas que fueron lanzadas contra los primeros artículos acusándolo de exaltar la violencia comunista. Merleau-Ponty se vuelve maquiaveliano para enrostrarle a sus críticos la falsedad de sus principios, diciendo que: "toda discusión seria del comunismo debe plantearse el problema, pues, como el mismo comunismo lo hace, es decir, no sobre el terreno de los principios, sino sobre el de las relaciones humanas." 24 Hay entonces un gesto maquiaveliano para extirpar el juicio político de la pureza de los principios y ponerlo en el seno del antagonismo social. En este gesto se incluye al marxismo como crítica concreta de la abstracción liberal. El liberalismo doctrinal se esfuerza por mantener la pureza de principios para mejor ocultar la opresión. En rigor, la crítica de Merleau-Ponty se sintetiza en la denuncia de la opresión y la injusticia de las sociedades occidentales nominalmente liberales. El ejemplo es extraído de las colonias. El liberalismo ingles o francés respeta los derechos humanos en Londres o París pero qué ocurre en Palestina o en Egipto, en Argelia o Túnez. Para juzgar a la URSS hay que ver el cuadro completo de la llamada "civilización liberal". Se trata, acercándose sorprendentemente a los discursos anticoloniales de un Césaire o un Fanon, de develar la hipocresía fundamental de las sociedades liberales. Hipocresía sustentada en un formalismo jurídico de prosapia kantiana que no es más que el complemento solemne de la violencia. El liberalismo está lejos de sustraerse a la violencia, y cuando transforma su doctrina en un dogma puede tornarse una ideología de guerra.

La superioridad del marxismo respecto al liberalismo surge de este reconocimiento explícito de la realidad del conflicto, de la violencia, de la sociedad desgarrada. Marx sabía que no era posible postular un universal $a$ priori porque eso significaba un ocultamiento del conflicto, un handicap inestimable para que las clases dominantes justifiquen su opresión. Por el contrario, se trataba de ir hacia lo particular encontrando en él la posibilidad de lo universal. Merleau-Ponty retoma la teoría marxista del proletariado y la

${ }^{23} \mathrm{El}$ prólogo fue escrito después de los capítulos que inicialmente se publicaron como artículos en Les temps modernes desde fines del 46 hasta fines del 47, cuando los artículos se convirtieron en libro. El mismo prólogo fue un artículo publicado en el número 22 de la revista, julio de 1947, bajo el titulo: Apprendre à lire.

${ }^{24}$ Merleau-Ponty, Maurice, Humanismo y terror, Buenos Aires, Leviatán, 1986, p. 9. 
distinción constitutiva de la violencia proletaria. Pero rápidamente pasa del comunismo teórico de Marx al comunismo concreto que se desarrolla en la Unión Soviética, y entonces surge el problema: el comunismo soviético está en contradicción flagrante con el comunismo de Marx. "Nos encontramos pues en una situación inextricable. La crítica marxista del capitalismo sigue siendo válida y es evidente que el antisovietismo reúne hoy la brutalidad, el orgullo, el vértigo y la angustia que han encontrado su expresión en el fascismo. Por otro lado, la revolución se ha inmovilizado sobre una posición de repliegue: mantiene y acrecienta el aparato dictatorial al mismo tiempo que renuncia a la libertad revolucionaria del proletariado en sus Soviets y en su Partido y a la apropiación humana del Estado. No se puede ser anticomunista, no se puede ser comunista." 25 He aquí el drama político/intelectual de Merleau-Ponty, y de toda una generación. Primero se realiza la crítica de la sociedad liberal burguesa apoyándose en Marx -y también, por qué no, en Maquiavelo-, y luego, cuando desde Marx se va al socialismo ruso se produce el estupor. ¿Qué hacer?

Nuestro autor va a elegir el suspenso, el attentisme marxiste, pero también va a buscar una definición de lo político que permita al mismo tiempo comprender la violencia y desear la libertad. Y dicha definición va a perseguirse -aunque esté camuflada bajo el ropaje de las amenas citas de Marx- a partir de un malestar con lo político marxista que, en el texto sobre Maquiavelo escrito dos años después se ve con más claridad a pesar de ser en muchos sentidos una versión condensada de Humanismo y terror.

En el prólogo, Merleau-Ponty se esfuerza por mostrar que su trabajo gira alrededor del problema de la legitimidad de la violencia y no de la justificación de la misma en aras de la construcción de una sociedad futura idílica. Sólo los que creen en la transparencia del decurso histórica pueden lanzar tan temeraria afirmación. No. La violencia no puede legitimarse por un ídolo llamado Historia; sin embargo, la violencia existe, acontece, es entonces vital reflexionar sobre ella, sobre sus diversos y divergentes modos. Por ende, hay un problema con la legitimación de la violencia que, para Merleau-Ponty, se condensa en una pregunta históricamente concreta: ¿Bujarin murió por la revolución, por una nueva humanidad?26 El drama de

${ }^{25}$ Merleau-Ponty, Maurice, Humanismo y terror, pp. 15-16.

26 Ibid., p. 28. 
Bujarin -ser fiel a uno mismo o plegarse al colectivo triunfante- pone en crisis la dialéctica marxista. Y ese drama emerge de la ascensión de lo político tout court. "La acción política es en sí impura, porque es acción de uno sobre otro y porque es acción entre varios"; "[g]obernar, como se dice, es prevenir, y la política no puede justificarse sobre lo imprevisto. Pero lo imprevisible existe. Esa es la tragedia"; “[]a maldición de la política consiste precisamente en esto: que debe traducir los valores en el orden de los hechos"27. Estas frases sintetizan el pensamiento político merleau-pontyano y su indudable raíz maquiaveliana. De allí, surgen dos consecuencias: 1) el político es un actor, representa un papel; 2) una política para ser buena tiene que triunfar, es decir, la política no puede justificarse por las intenciones, ni por un acuerdo entre los proyectos y la conciencia subjetiva. Hay entonces un desacople originario que define el quehacer político.

Merleau-Ponty ancla su noción de lo político en la pluralidad humana. Pero esa pluralidad no puede cobijarse en el paraguas de una racionalidad práctica porque está en todo momento corroída por lo imprevisible (contingente) y por la violencia entendida como lucha de clases. El carácter contingente de la acción política le quita toda legitimidad trascendente al poder, volviendo tan legítimos el derecho del poder como el de la oposición ${ }^{28}$.

Nuestro autor no se priva de citar a Montaigne, pero en todo momento ronda la figura de Maquiavelo en el clima de ideas que dirige el prólogo. En quién sino están inspiradas las páginas sobre el político como actor, la centralidad de la eficacia en política y la soldadura entre la libertad y lo imprevisible. Bujarin recuerda a los personajes que desfilan por los escritos maquiavelianos, ya que se toma su drama como símbolo y se tiende a desechar el aspecto propiamente histórico. Este corrimiento fue señalado críticamente por Lefort en su estudio preliminar a Humanismo y terror. Pero, sorprendentemente, Lefort no se detiene en este ademán maquiaveliano que busca símbolos de lo político y no un ocultamiento de los efectivos acontecimientos históricos, como le reprocha el discípulo a su viejo maestro.

27 Ibid., pp. 26-29.

28 " $\mathrm{La}$ contingencia del porvenir, que explica las violencias del poder, le quita al mismo tiempo toda legitimidad, o legitima igualmente la violencia de los opositores. El derecho de la oposición es exactamente igual al del poder" (Ibid., p. 30). 
No hay duda de que el problema de la violencia en relación a la concepción merleau-pontyana de lo político bebe las aguas de las escabrosas fintas maquiavelianas, y muy singularmente despierta la remembranza del relato sobre el asesinato de Remo y las reflexiones que le deparan al pensador florentino. ${ }^{29}$

Por el mismo sendero van sus diatribas contra el moralismo kantiano que ensombrece a la política francesa - de derecha a izquierda- a partir del implacable impacto de las dos guerras mundiales. Hay un rechazo de la política y un intento por irresponsabilizar a los hombres públicos bajo el velo de las buenas maneras. Merleau-Ponty sostiene que sus afirmaciones ya se hallaban en el corazón del pensamiento griego, en el juicio a Sócrates, en la tragedia de Edipo. "Toda la tragedia griega sobrentiende esta idea de un azar fundamental que nos hace a todos culpables y a todos inocentes porque no sabemos qué hacemos"30. Es evidente cómo el pensador francés concibe el estrecho lazo entre la política y la tragedia. Esta imbricación es la que conocían perfectamente los griegos y que nuestro autor saca de nuevo a relucir en sus reflexiones sobre el problema del comunismo. Reflexiones que surgen de la atribulada convicción acerca de la imposible solución definitiva de la vida en común, es decir, la efectiva construcción de una sociedad sin conflictos desgarradores y, al mismo tiempo, la irrenunciable apuesta por una vida política libre.

A partir de estas líneas podemos sospechar que el nombre de Max Weber debe aparecer. Y aparece. Merleau-Ponty recurre a él, apoyándose en un libro de Raymond Aron ${ }^{31}$, para apropiarse de las conocidas meditaciones weberianas acerca de los dilemas del hombre de acción, de la ética de la responsabilidad y la convicción, del politeísmo de los valores. Ese mismo politeísmo es el que sostiene Merleau-Ponty en relación a la Unión Soviética y Occidente con el fin de hacer más ancho el camino que lleve a una vida política libre sin las ilusiones simétricas de una filosofía dogmática de la

29 "Y que Rómulo sea de los que merecen excusa por la muerte de su hermano y de su compañero, y que lo hizo por el bien común y no por ambición, lo demuestra el hecho de que en seguida estableció un senado que le aconsejase y de acuerdo con el cual tomaría las decisiones" (Maquiavelo, Nicolás, Discursos sobre la primera década de Tito Livio, Madrid, Alianza, 1987, p. 57).

${ }^{30}$ Ibid., p. 33.

31 Aron, Raymond, La sociología alemana contemporánea, Buenos Aires, Paidós, 1965. 
historia y de una libertad ídolo; ambas, meras fachadas al servicio de la opresión.

\section{III}

Merleau-Ponty emplea con frecuencia en sus textos políticos la palabra bumanismo. Lo hace, por supuesto, con un objetivo preciso. En sus trabajos de filosofía este concepto no es trabajado positivamente. Más aún: el humanismo entendido como antropología filosófica es sometido a una creciente crítica desde las páginas dedicadas a la libertad en la Fenomenología de la percepción hasta Lo visible y lo invisible o el prólogo a Signos, donde Merleau-Ponty se despega explícitamente de cualquier vinculación con el humanismo antropológico ${ }^{32}$. La crítica merleau-pontyana a la posibilidad de una conciencia constituyente, trascendental, es similar a lo que luego Foucault llamará "el sueño antropológico". Sin embargo, en sus trabajos políticos la palabra "humanismo" vuelve una y otra vez. Por ejemplo, en El hombre y la adversidad, donde la adversidad, la resistencia de lo sensible, toma más fuerza y pone en apuros al humanismo optimista que se quiere heredero de la Ilustración. Por eso, a ese humanismo idealista, de sobrevuelo, Merleau-Ponty le antepone un nuevo bumanismo que interiorice la realidad de la contingencia, asuma la mélange del espíritu y el cuerpo, el obrar del lenguaje. Los ejemplos de esta nueva etapa histórico filosofica que requieren como correlato otro bumanismo se extraen del psicoanálisis freudiano, la literatura proustiana, la fenomenología, de la crisis del marxismo revolucionario y de la ascensión de la lógica de la Guerra Fría ${ }^{33}$.

Podrá argüirse que nuestro autor va paulatinamente modificando su lectura del humanismo, vía Heidegger, hasta llegar a las páginas de Lo visible y lo invisible. Aunque también hay otra lectura posible, porque el modo en que se presenta al humanismo en los diversos textos señalados no parece coincidir demasiado con la idea de una metafísica humanista. Es más: el

32 En la última nota de trabajo de Lo visible y lo invisible dirá: "Hay que describir lo visible que se realiza a través del hombre, sin que sea en modo alguno antropología (por tanto, en contra de Feuerbach-Marx 1844)" (Merleau-Ponty, Maurice, Lo visible y lo invisible, Barcelona, Seix-Barral, 1966, p. 320).

${ }^{33}$ Cfr. Merleau-Ponty, Maurice, "El hombre y la adversidad”, en Signos, pp. 301-302. 
nuevo humanismo, humanismo serio, real, ha interiorizado, hecho propia, la crítica al humanismo como technè.

En efecto: Heidegger en su conocida Carta sobre el bumanismo define todo humanismo como una metafísica, una metafísica que olvida la pregunta por el ser y se inclina hacia la realidad del ente para terminar en el terreno del dominio técnico ${ }^{34}$. Estás paginas tuvieron un gran impacto en el escenario filosófico, sobre todo francés. Las filosofías que durante los años 60 se despegaron de la fenomenología encontraron una viva fuente de legitimidad en la carta heideggeriana. La fenomenología merleau-pontyana, pese a sus sutilezas, también cayó bajo la crítica del filósofo alemán según sus entusiastas lectores; dicho de otra manera: su filosofía fue expulsada del debate francés acerca del hombre. ${ }^{35}$ Podemos sospechar que lo mismo habría ocurrido alrededor de la tematización merleau-pontyana sobre la posibilidad de un bumanismo real; en consecuencia, la posibilidad de otra lectura debe sortear el obstáculo heideggeriano.

Encontramos esta alternativa en un ensayo de Lefort dedicado al nacimiento de la ideología y el humanismo ${ }^{36}$. En él se realiza una explícita crítica a la generalización heideggeriana que sindica a todo humanismo como metafísica. Lefort sospecha del gesto heideggeriano de apilar diversos humanismos en la estela de la ceguera metafísica y concentra su crítica en el modo de trabajar la bumanitas renacentista. Heidegger reduce el humanismo a su representación, en el sentido de un renacimiento de la romanitatis, y así excluye de su mirada al suceso florentino, al humanismo cívico, suceso que está regido por una apertura hacia el pasado que converge en una dimensión histórica de la experiencia que no coincide plenamente con su

34 "Todo humanismo o se funda en una Metafísica o se convierte a sí mismo en el fundamento de una Metafísica. Toda determinación de la esencia del hombre que supone la interpretación del ente sin la pregunta por la verdad del ser -sea sabiéndolo o no- es metafísica" (Heidegger, Martín, La carta sobre el bumanismo, Buenos Aires, Ediciones del 80, 1988, p. 74).

35 Ver: Derrida, Jacques, "Los fines del hombre", en Márgenes de la filosofía, Madrid, Cátedra, 1998.

${ }^{36}$ Lefort, Claude, "El nacimiento de la ideología y el humanismo", en Las formas de la bistoria, México, FCE, 1988, pp. 199-235. 
representación. ${ }^{37} \mathrm{El}$ reproche clave de Lefort a las tesis heideggerianas se ancla en el afán identificador entre el humanismo y su representación -la esencia del hombre- y la consecuente reducción de la diversa saga humanista a un pensamiento de la técnica que olvida el ser. Nuestro autor concluye el sentido de su crítica de la siguiente manera: "el humanismo romano requiere ya una interrogación de lo político, no como un conjunto de significaciones empíricas, localizables a cierta distancia de la llamada cultura, sino como institución de lo social y autodescripción de lo social, articulación y representación de las señalas de la existencia". ${ }^{38} \mathrm{La}$ mirada heideggeriana sobre el humanismo renacentista adolece de esta interrogación sobre lo político, y será justamente el carácter político de ese humanismo el que marcará su aspecto distintivo. Los humanistas florentinos descubren en su visita al pasado romano el fundamento político de la institución de lo social y ubican la bumanitas no en la esencia del hombre como ente, sino en la Ley como libertad. Lo político del humanismo cívico evita la caída en la ceguera metafísica y abre las puertas de un pensar sobre el ser.

Dimos este rodeo por Lefort para observar como hay una tradición humanista que puede sustraerse a la cerrazón antropologizante realizando una apertura hacia lo político. Esta tradición tiene su punto más alto en Maquiavelo -aunque se sabe que éste rompe con varios presupuestos del humanismo cívico-, a raíz de su profunda meditación sobre la configuración política de lo real. Por eso, creemos, que cuando Merleau-Ponty se refiere al humanismo real, serio, tiene in mente esta constelación. No se trata de un humanismo en el sentido metafísico que Heidegger había convocado a abandonar, sino de un humanismo político que hace propio el abismo de la

37 Citamos el párrafo de Heidegger en el que se basa Lefort: "El llamado Renacimiento de los siglos XIV y XV en Italia es una renascientia romanitatis. Porque importa esta romanitas, se trata de la humanitas y por eso la paideia griega. Pero el griego es visto siempre en su forma tardía, y aun esta misma, a la romana. También el homo romanus del Renacimiento está en oposición al bomo barbarus. Pero lo inhumano es aquí el pretendido barbarismo de la escolástica gótica del Medioevo. Al humanismo entendido históricamente pertenece siempre por ello un studium bumanitatis que en determinada modo se remite a la Antigüedad y que siempre se convierte en un revivir de lo griego" (Heidegger, Martín, Carta sobre el bumanismo, p. 73).

${ }^{38}$ Lefort, Claude, "El nacimiento de la ideología y el humanismo", p. 234. 
contingencia y también la apertura de la libertad como intersubjetividad práctica en conflicto y comunión. El humanismo y la libertad no refieren a la consabida metafísica de la conciencia -que Merleau-Ponty no se cansa de criticar en Sartre-; más bien apelan a la existencia política, a la institución política de la libertad.

Dichas reflexiones sobre el humanismo, la institución política y la libertad pueden perfectamente considerarse parte del momento maquiaveliano. O mejor: hay una exacta simetría entre la noción de bumanismo politico y la de momento maquiaveliano. Éste es el sentido del concepto de humanismo en los escritos políticos merleau-pontyanos, ya que no se entiende la bumanitas como una conciencia transparente, plena presencia a sí, sino como "virtù sin resignación"39.

Miguel Abensour realiza la misma cita para situar a Merleau-Ponty en la tradición que va de Marx a Maquiavelo ${ }^{40}$. Y en este sentido podemos preguntarnos por la vinculación de Marx con el denominado humanismo político. Sabemos que Abensour pone a un cierto Marx en esta saga. El joven Marx de la crítica a la filosofía del derecho de Hegel y el maduro de la comuna de París estarían dentro de ese singular momento maquiaveliano que se anima a escrutar el enigma de lo política en clave de una democracia contra el Estado. De acuerdo a la hermenéutica sagaz de Abensour, si nos focalizamos en este sorprendente Marx político, no habría necesidad de transitar el camino que nos conduzca a Maquiavelo, ya que en determinados textos marxianos se estaría reflexionando de cara a lo político. Claro que para ello, es vital desprenderse de la filosofía de la historia, de la teoría del proletariado, de la crítica económica de la política, que anidan en Marx. Por tanto, sólo es "recuperable" un cierto Marx: el Marx maquiaveliano.

Nosotros señalamos que Merleau-Ponty busca maquiavelizar a Marx dando primacía a la dimensión de la contingencia frente a la siempre presente inclinación marxista por cobijarse en las certezas de una metafísica de la historia. No hay duda de que este gesto no alcanza, por no estar del todo predispuesto a abandonar el magma de la Revolución, para operar una reducción como la que décadas después va a emprender Abensour. Aunque

${ }^{39}$ Merleau-Ponty, Maurice, prefacio a Signos, p. 45.

40 Abensour, Miguel, La democracia contra el Estado, Buenos Aires, Colihue, 1998, p. 122. 
es factible señalar que, si, en el ensayo de Abensour, el joven Marx a partir de su combate frontal contra la representación teológica del mundo redescubre lo político como democracia contra el Estado, en el pensamiento de Merleau-Ponty, a raíz de su combate contra el marxismo dogmático, se redescubre la dimensión propia de lo político como humanismo de la contingencia y la virtù. Pero este develamiento va acompañado todavía por la idea de que el marxismo es -apelando a un sartrismo avant la lettre- la filosofía insuperable de nuestro tiempo.

Queda por saber cómo van a conjugarse estás dos constelaciones, a saber, el humanismo político y la filosofía proletaria de la historia; pero ese será un tema que dejamos para futuras investigaciones.

Recibido: 10/2011 Aceptado: 03/2012 